\title{
Risk factors for Tuberculosis in Mwea West Sub-County, Kirinyaga County, Kenya
}

\author{
Dennis Muriuki ${ }^{1}$, Dennis Butto ${ }^{2}$, Mary Amatu ${ }^{3}$ \\ ${ }^{1}$ (Kerugova Country Refferal Hospital, Country Government of Kirinvaga, Kenya \\ ${ }_{2}^{2}$ (Department of Clinical Medicine, Kirinvaga University, Kenya) \\ ${ }^{3}$ (Department of Health Promotion, County Government of Nairobi- Kenya)
}

\begin{abstract}
In the year 2012, 89,568 cases of Tuberculosis (TB) were notified in Kenya. Using this figure, World health Organization (WHO) ranked the country 15th out of 22 countries with high TB burden. Mwea west is one of the sub counties in Kenya in high TB prevalence and this descriptive cross sectional study attempted to establish those risk factors associated with this. The result revealed that about $80 \%$ of the respondents had ever suffered from TB with $17 \%$ and $3 \%$ reporting that they had contracted the disease twice and more than twice respectively. Additionally, $40 \%$ of the respondents reported that at least one of their family members had contracted TB. The high level of TB in this population is an acceptable in this day and age. HIV/AIDS infection was conspicuously present in over $70 \%$ of respondents with TB. Other lifestyle issues identified included smoking 50\%, alcohol abuse $62 \%$ and low knowledge on TB transmission. Health promotion interventions aimed at behavior modification should be scaled up and an analytical study determine the relationships between social demographics and prevalence should be carried out.
\end{abstract}

Keywords - Tuberculosis, HIV/AIDS, Immunization, smear positive TB

\section{INTRODUCTION}

Tuberculosis (TB) is one of the oldest diseases known to affect humans and a major cause of death worldwide. It is a global public health concern but majority of cases occur in the world's poorest nations, who struggle to cover the costs associated with management and control programs [1]. According to the WHO, 2012 annual TB report, there were 8.7 million incident cases with a range of 8.3-9.0 million. In 2011, 1.1million cases were among people living with HIV. Over the same year there were 6.2 million notified cases of TB against an estimated 8.7 million cases, representing a case detection rate (CDR) of $66 \%$. There were an estimated 1.4 and 0.43 million TB related deaths among HIV sero-negative and positive respectively. Of the new sputum smear positive TB cases registered in $2010,87 \%$ were successfully treated

The earliest recorded human case of tuberculosis dates back 9000 years. Early treatment modalities, such as bloodletting, were replaced by sanatorium regimens in the late 19th century. The discovery of streptomycin in 1943 launched the era of antibiotic treatment for TB. Over subsequent decades, the discovery of additional agents and the use of multiple-drug regimens allowed progressive shortening of the treatment course from years to as little as 6 months with the regimen for drug-susceptible TB. To be infected with the tubercle bacillus a person must be exposed to an infectious case of TB. This follows several factors that increase the risk for infection [2].

The risk factors for exposure to the tuberculosis bacillus incidence of infectious $\mathrm{TB}$ in the population/community, average duration of infectiousness of cases, number of case/contact interactions over time, population density, family size, poverty, and overcrowding. Following exposure to the bacillus the risk of infection is related to the extent of contact and the following determines the risk following exposure; Bacillary load of infectious cases (smear positivity), extent of contact with infectious cases (Proximity to infectious case, length of contact with infectious case), contact environment (Air clearance (ventilation)- affects dispersion of bacilli, sunlight [2]

A study done on patient's knowledge, attitude and practice regarding TB in Uganda established that $79.9 \%$ of repondents recognized that inhaled droplets through coughing and sneezing was the common source of TB infection[3].

Kenya is ranked 15th among the 22 high TB burden countries that account for $80 \%$ of the global TB burden and 5th in Africa. In 2012, the country notified a total of 103, 159 TB cases (all forms of tuberculosis) of whom 39\% were also HIV infected. Tuberculosis treatment results for TB patients started on treatment in 2010 showed a treatment success of $87 \%$ for new smear positive pulmonary TB cases [4] 
According to the National Tuberculosis, leprosy and lung disease unit report 2015, there has been a steady increase in the number of tuberculosis patients particularly since the early 90's. This rising number of tuberculosis cases poses a major threat to the health and the economy of this country. The case notification rate has steadily increased from 54 per 100,000 in 1991 to 326 per 100,000 in 2009 . The peak age group for both males and females in 2006 was 25-34 years, the economically productive and sexually active age group with a female to male ratio of $1: 4$

Currently the HIV sero-prevalence among the tuberculosis patients was $44 \%$ in 2009 . The number of TB cases has stabilized and decline is beginning to be noticed but this will become evident in the next few years or so to come. The annual decrease in TB case notification rate is about $8 \%$. By the end of 2009 , all forms of TB cases notified in the public sector were 110,065 [5]

WHO estimates that only $80 \%$ of the TB cases are being detected in Kenya, indicating that the remaining $20 \%$ undetected cases continue to transmit TB. This increasing number of TB cases is thought to be largely associated with the growing HIV epidemic. Poverty and poor malnutrition are major factors fuelling the spread of tuberculosis in Kenya, health experts say. Slum dwellers in Nairobi and other urban areas face the highest risk and contribute 80 percent of the total Tb burden in the country [1].

Number of TB patients attending hospital is increasing hospital workload and at the same time creating a risk of TB infection to the hospital staff and to other patients with greater risks like PLWHA, diabetics and infants among others. By identifying factors fuelling TB spread, prevention and control can be achieved at community level and this would be an achievement both at community level and National level at large. Some of the money spent by the government to treat TB patients would be channeled to other developmental projects. Productivity at community level would also increase because of the low mortality and morbidity due to TB decrease. The overall would be increase in economic growth, improved life expectancy and a healthy Nation[6]. Mwea west Sub-County covers an area of approximately $231 \mathrm{Km} 2$ with a population of approximately 100,000 people which accounts for about $19 \%$ of the total county population [7]. Of the total land coverage, it is estimated that $90 \%$ is used for rice farming and the area is under intensive irrigation throughout the year. Therefore, only $10 \%$ of the land is available for housing of approximately 100, 000 people and this explains why they have resulted to villages for settlement and hence over-population. This study was done to establish the prevalence of TB and other associated risk factors in Mwea West to inform public health interventions.

\section{MATERIALS AND METHODS}

\subsection{The Study Area}

This study was carried out in Mwea Sub county within the County Government of Kirinyaga , Kenya.

\subsection{Study Population}

The study population consisted of all TB patients seeking health services in the 8 heath centers in Mwea Sub County.

\subsection{Inclusion Criteria}

Those included in the study were all TB patients who gave informed consent and were not too ill during the interview.

\subsection{Study Design}

The study was descriptive, cross section study.

\subsection{Sample Size Determination and Sampling Techniques}

A sample size of 114 was determined using Fishers el al formula. Four out of the 8 health facilities in Mwea West Sub County were randomly picked for the study. Proportionate sample for each of the four facilities were subsequently calculated. Mutithi Health Center; 38, Ciagini dispensaries; 16, Thiba Health Center; 47 Njegas dispensary; 13. Data was collected using structured questionnaires among patients referred to the TB Clinics in these health facilities for investigation and management.

\subsection{Ethical considerations}

Clearance was sought from the following institutions: Egerton University and Ministry of Education, Science and Technology. Informed consent was obtained from the respondents with assurance of confidentially. Coded numbers were used instead of names of the subjects. 


\subsection{Data Collection Methods and Research Instruments}

Before this study was carried out, research assistants were trained and pre-testing of research tools done in Kutus dispensary in a similar population. The actual collection of data was done over a period of one month.

\subsection{Data Management and Analysis}

Data collected from each of the health facilities was coded before entry and captured using integrated micro-computer processing system (IMPS) version 3.1. This was done because the IMPS had fewer outliers and data editing is done on the screen during entry. Then the data was converted to SPSS Program version 17.

\section{RESULTS AND DISCUSSION}

A total of 114 respondents were interviewed on socio-demographic, knowledge and risk factors for TB and treatment compliance.

3.1 Age of the respondents.

Table 1. Age groups of respondents

\begin{tabular}{|l|c|c|}
\hline Age Group & Frequency $\mathbf{n = 1 1 4}$ & $\mathbf{( \% )}$ \\
\hline $\begin{array}{l}\text { Below } 10 \\
\text { years }\end{array}$ & 8 & 7.0 \\
\hline $10-20$ years & 5 & 4.4 \\
\hline $21-30$ years & 19 & 16.7 \\
\hline $31-40$ years & 58 & 50.9 \\
\hline 41-50 years & 14 & 12.3 \\
\hline Over 50 years & 10 & 8.8 \\
\hline Total & 114 & 100.0 \\
\hline
\end{tabular}

Slightly more than half of the respondents (50.9\%) were aged 31-40 years. $8.8 \%$ were aged over 50 years. Those aged below 10 years were $7 \%$.Tuberculosis disease has no age group discrimination and the above results prove that. However, in this study, slightly more than half belonged to a certain age group and this could probably be due to factors that were beyond patient's control

\subsection{Gender of the respondents}

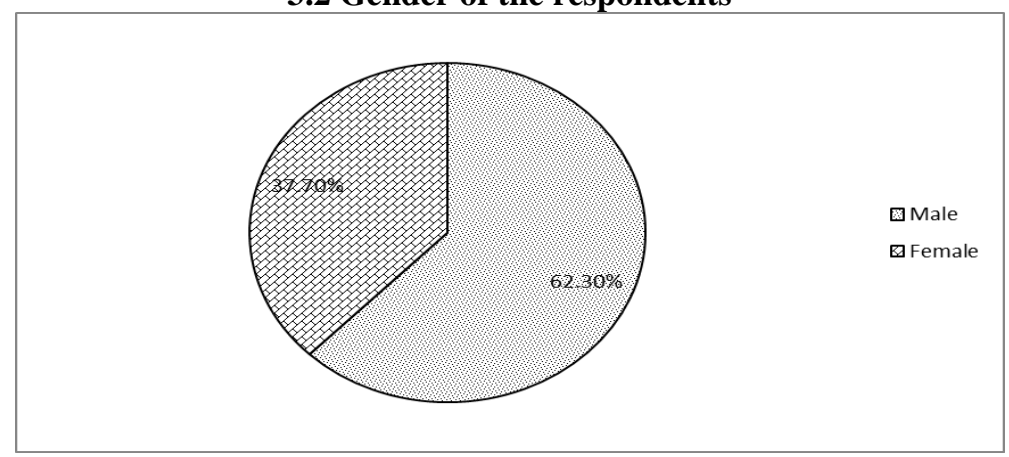

Figure 1.. Distribution of the respondents by gender

Majority (62.3\%) were male while $37.7 \%$ were female respondentsMost of the patients were men and this might be due to the fact that men are affected more than females. This pattern has also been witnessed by other studies $[8,9]$. It is also true that those who smoked cigarette and also took alcohol in this study were men hence more risk factors

\subsection{Level of education of respondents}

Figure 2. Distribtion of respondents by their level of educationHalf of the respondents $(50.9 \%)$ of the respondents had attained primary education as their highest level. They were followed by those who had attained non-formal education at $23.7 \%$, those that had reached secondary school were $16.7 \%$ and finally $8.8 \%$ who had attained college or university education. The highest level of education most respondents had attained was primary school with the least being tertiary school education. Though the above presentation shows average academic qualifications on part of the respondents, this is often not enough when it comes to disease prevention and management. This is because most of these skills are attained at tertiary level or at least secondary level. This therefore places most of the respondents in the study and the community alike in harm's way. Most of the 
population that did not have access to advanced education was prone to TB infection since they are often not aware of the transmission of TB and hence can easily contract the illness.

\subsection{Occupation status of the respondents}

Table 2 Distribution of respondents by their occupation

\begin{tabular}{|l|c|c|}
\hline Occupation & Frequency n=114 & $\mathbf{( \% )}$ \\
\hline Casual laborer & 51 & 44.7 \\
\hline Self employed & 21 & 18.4 \\
\hline Employed & 18 & 15.8 \\
\hline Unemployed & 8 & 7.0 \\
\hline Household chores & 16 & 14.0 \\
\hline Total & $\mathbf{1 1 4}$ & $\mathbf{1 0 0 . 0}$ \\
\hline
\end{tabular}

The greatest proportion of the respondents were casual laborers (44.7\%) followed by self-employed at $18.4 \%$ then employed at $15.8 \%$. Those who stayed at home doing household chores were $14 \%$ and the unemployed were $7 \%$.

\subsection{Approximate household monthly income}

Table 3. Distribution of respondents by their approximated monthly income

\begin{tabular}{|c|c|c|}
\hline Monthly income & Frequency n=114 & $(\%)$ \\
\hline Less than 2,500 & 14 & 12.3 \\
\hline $2,500-10,000$ & 46 & 40.4 \\
\hline $11,000-20,000$ & 33 & 28.9 \\
\hline $21,000-30000$ & 9 & 7.9 \\
\hline $31000-40000$ & 102 & 89.5 \\
\hline 40,000 and above & 12 & 10.5 \\
\hline $\begin{array}{l}\text { Total } \\
\end{array}$ & 114 & 100.0 \\
\hline
\end{tabular}

According to the table above, most respondents households (45.1\%) were earning an average monthly income of Kenya shillings 2,500-10,000 monthly. 32.4\% were earning between 10,000 to 20,000 every month and the least $(11 \%)$ were those that earned over 40,000 monthlyMost respondent's household income was between 2,500-10,000 Kenya shillings, monthly. Followed by 10,000 to 20,000 monthly .The greatest proportion of the respondents were casual laborers followed by self-employed, then employed and those who stayed at home doing household chores and were unemployed were the least. This depicts that few respondents could afford basic medical care and hence falling prey to infectious diseases such as TB [10].

\subsection{Frequency of suffering from TB}

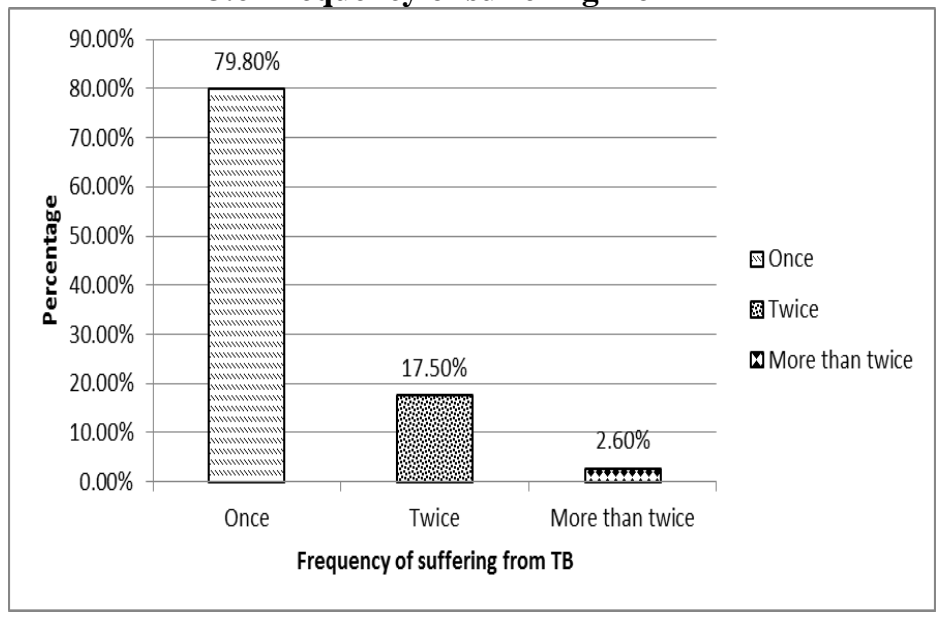

Figure 3 Distribution of respondents by frequency of suffering from TB

Majority of respondents $(79.8 \%$ ) had suffered from TB once. $17.5 \%$ had suffered twice and $2.6 \%$ had suffered more than twice in their lifetime. 


\subsection{Presence family members with history of TB}

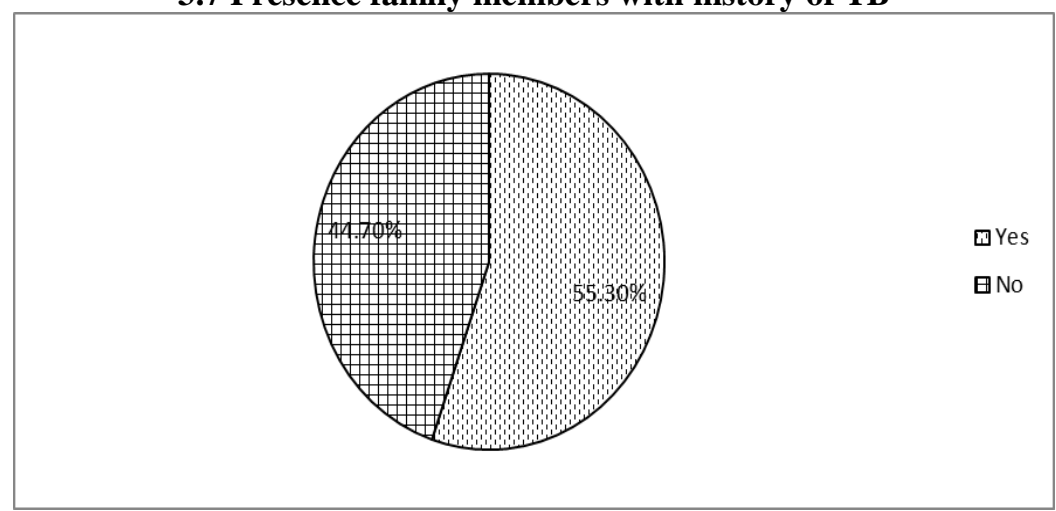

Figure 4 Distribution of respondents by the presence of family member with history of TB

$55.3 \%$ of the respondents said that there were other family members of the household with history of having contacting TB in the past. $44.7 \%$ said there were no family members with history of TB.Incidence of infectious TB in the population/community, average duration of infectiousness of cases, number of case/contact interactions over time, population density, family size, poverty, and overcrowding are risk factors of TB infection. In this study, more than half had more than 5 people in their households and in that population, more than half had history of other family members ever having suffered from TB. Large family size was evident in this region and this might have increased the risk of an individual in that family contracting tuberculosis at any one point in their lives $[11,12]$.

\subsection{Respondents who suffer from other chronic illnesses}

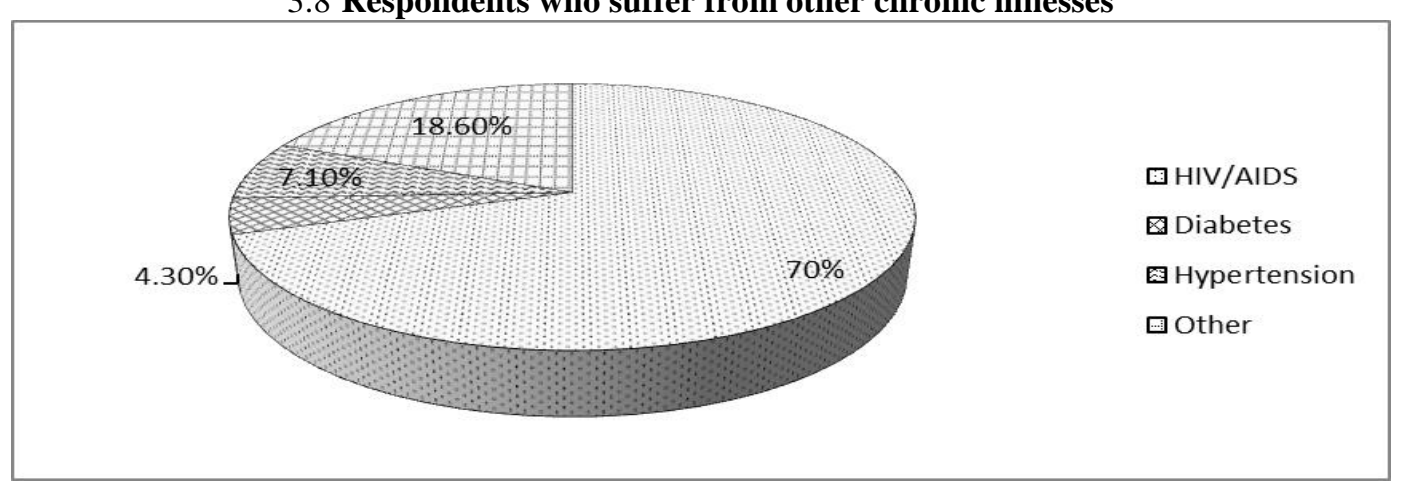

Figure 5. Distribution of respondents by the nature of chronic disease suffered

Out of the $61.4 \%$ who suffer from other chronic illnesses, the most mentioned chronic illness as suffered by the respondents was HIV/AIDS which was suffered by $70 \%$ of the respondents. It is important to note that this percentage is out of those who said they were suffering from other chronic illnesses other than TB. $18.6 \%$ said they were suffering from other illnesses other than the one mentioned in the questionnaire, $7.1 \%$ said hypertension and $4.3 \%$ said diabetes.

Most of the patients had other chronic illness (es) other than tuberculosis where the most mentioned chronic illness in the study was HIV/AIDS. In HIV/AIDS era, tuberculosis cases have increased probably due to the fact that HIV/AIDS is an immunosuppressive condition hence increasing the risk of contracting the disease. Several studies have also found associations between TB and presence of other chronic infections [13, 14].

\subsection{Respondents who have ever smoked}

Table 4 Distribution of respondents by whether they had ever smoked

\begin{tabular}{|l|c|l|}
\hline Smoking & Frequency $\mathbf{n = 1 1 4}$ & $\mathbf{( \% )}$ \\
\hline Have smoked & 57 & 50.0 \\
\hline Haven't smoked & 57 & 50.0 \\
\hline Total & $\mathbf{1 1 4}$ & $\mathbf{1 0 0 . 0}$ \\
\hline
\end{tabular}


$50 \%$ had ever smoked and 50\% had never smoked before. According to other studies conducted in Africa and beyond [15, 16], more risk factors to contracting tuberculosis include malnutrition, diabetes, silicosis, alcoholism and tobacco smoking. In this study most respondents had ever taken alcohol while half had ever smoked. This placed majority of the smokers and alcoholics at risk of contracting TB.

\subsection{Knowledge on transmission of TB}

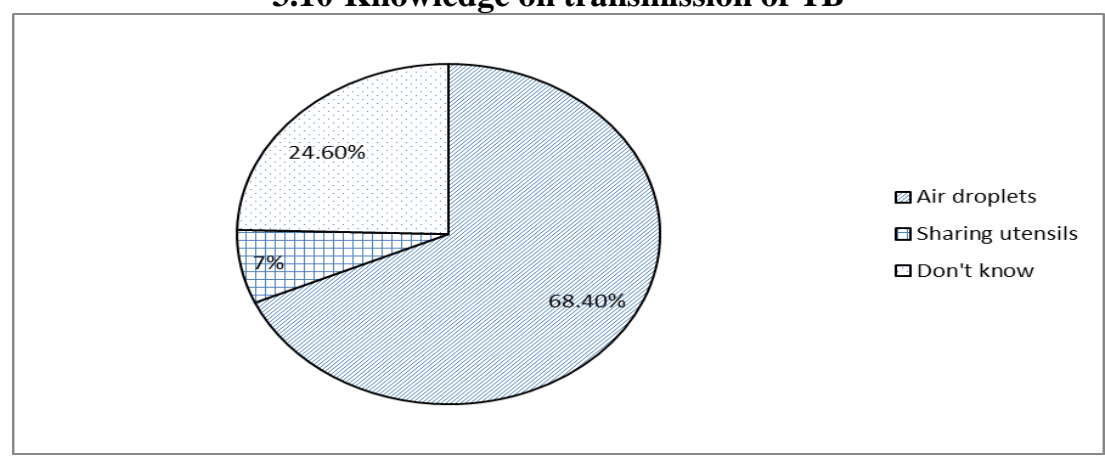

Figure 6. Distribution of respondents by their knowledge on TB transmission

$68 \%$ of the respondents said that TB was transmitted by air droplets, $24.6 \%$ did not know and $7 \%$ said by sharing utensils. Most of the respondents said that TB was transmitted by air droplets, while the least number said by sharing utensils. This presented rather above average knowledge and hence the majority of respondents could not have contracted TB for lack of knowledge on transmission routes and modes. Knowledge on transmission has been found to be proportionately associated with reduction on transmission rates [17].

\subsection{Overcrowding}

Figure 7 Distribution of respondents by the number of household members

More than half $(52.6 \%)$ had more than 5 people in their households. $25.4 \%$ had 3 to 5 people, $14 \%$ had less than 3 persons. Overcrowding has been found to increase the transmission rates for tuberculosis in other studies [18].

\section{CONCLUSION AND RECOMMENDATION}

\subsection{Conclusion}

The prevalence of TB in the study area was high with all the respondents having been chosen from a population of TB patients. Despite this, they had other family members with history of having ever suffered from TB and village members as well. Most of the respondents with TB were casual laborers presenting very low socio-economic status. Though respondents in the study presented acceptable levels of knowledge on TB risk factors, there were factors that were beyond them and seemingly placing them on harm's way. These included large household size and overcrowding in their residences.

\subsection{Recommendations}

The county government of Kirinyaga should put more emphasis on prevention of TB rather than treatment alone. This can be made possible by dispatching health officials to conduct community awareness campaigns to create awareness on how community members can prevent new infections of TB. Apart from this, the county government should set aside funds in its budget dedicated primarily to management of TB. Community based organizations and community health workers should make efforts to educate people at the community level on the risk factors of TB infection so as to make known to individuals, what they should and should not do with regard to controlling and preventing new infections. Those suffering from TB should be educated on safe practices of living with $\mathrm{TB}$ in the family so as not to infect other family members. Health facilities should enforce the need for patients of TB to adhere to treatment in order to reduce the chances of developing resistance to drugs. Those who are not infected should be educated on the preventive measures of avoiding infection of TB. Furthermore, the national TB control program should consider co-ordinating advocacy, communication and social mobilization activities on the communities to improve knowledge of patients, to reduce misconceptions, and prevent transmission of TB in the community. These measures can be made possible by the government through ministries of health and special programmes as well as other stakeholders. 
[1] Global TB control report 2012. Available at.

\section{REFERENCES}

http://apps.who.int/iris/bitstream/10665/75938/1/9789241564502_eng.pdf]. Accessed 12 December 17, 2014

[2] Lienhardt C, Fielding K, Sillah J, Bah B, Gustafson P, Warndorff D, et al. Investigation of the risk factors for tuberculosis: a case-control study in three countries in West Africa. Int J Epidemiol. 2005;34(4):91423. doi: 10.1093/ije/dyi100. [PubMed] [Cross Ref

[3] Lienhardt C, Fielding K, Sillah J, Tunkara A, Donkor S, Manneh K, et al. Risk factors for tuberculosis infection in Sub-Saharan Africa. Am J Respir Crit Care Med. 2003;168(4):448-55. doi: 10.1164/rccm.200212-1483OC. [PubMed] [Cross Ref]

[4] Kenya Ministry of Health's National leprosy and Tuberculosis treatment Guidelines. (July, 2013) Division of leprosy, Tuberculosis and lung disease.

[5] CDC . Department of Health EAW. Atlanta, Georgia: Public Health Service; 1985. Public health mycobacteriology: a guide for the level III laboratory control CFD.

[6] Creswell J, Raviglione M, Ottmani S, Migliori GB, Uplekar M, Blanc L, et al. Tuberculosis and noncommunicable seases:neglected links and missed opportunities. Eur Respir J. 2011;37(5):1269-82. doi: 10.1183/09031936.00084310. [PubMed] [Cross Ref]

[7] Kenya Ministry of Health's Guidelines for TB infection Prevention and control for Health Care workers in Kenya. (July, 2014) Division of leprosy, Tuberculosis and lung disease.

[8] World Health Organization (2009) Global tuberculosis control - surveillance, planning, financing. Geneva, Switzerland: WHO

[9] Tumwesigye NM, Kasirye R. Gender and the major consequences of alcohol consumption in Uganda. In: Obot I, Robin R, editors. Alcohol, gender and drinking problems. World Health Organization: Geneva; 2006. pp. 189-208

[10] Centers for Disease Control and prevention's Tuberculosis Data and Statistics. (2014) Division of Tuberculosis Elimination.

[11] Corbett EL, Bandason T, Cheung YB, Munyati S, Godfrey-Faussett P, Hayes R, et al. Epidemiology of tuberculosis in a high HIV prevalence population provided with enhanced diagnosis of symptomatic disease. PLoS Med 2007;4(1). [PMC free article] [PubMed]

[12] Singh J, Sankar MM, Kumar S, Gopinath K, Singh N, Mani K, et al. Incidence and prevalence of tuberculosis among household contacts of pulmonary tuberculosis patients in a peri-urban population of South Delhi, India. PloS one 2013, 8(7). [PMC free article] [PubMed]

[13] Kibirige D, Ssekitoleko R, Mutebi E, Worodria W. Overt diabetes mellitus among newly diagnosed Ugandan tuberculosis patients: a cross sectional study. BMC Infect Dis. 2013;13(122):1471-2334. [PMC free article] [PubMed]

[14] Creswell J, Raviglione M, Ottmani S, Migliori GB, Uplekar M, Blanc L, et al. Tuberculosis and noncommunicable diseases: neglected links and missed opportunities. Eur Respir J. 2011;37(5):1269-82. doi: 10.1183/09031936.00084310. [PubMed] [Cross Ref]

[15] Tumwesigye NM, Kasirye R. Gender and the major consequences of alcohol consumption in Uganda. In: Obot I, Robin R, editors. Alcohol, gender and drinking problems. World Health Organization: Geneva; 2006. pp. 189-208.

[16] Ryan H, Trosclair A, Gfroerer J. Adult current smoking: differences in definitions and prevalence estimates-NHIS and NSDUH, 2008. J Environ Public Health 2012;91:83-68. [PMC free article] [PubMed]

[17] Lienhardt C. From exposure to disease: the role of environmental factors in susceptibility to and development of tuberculosis. Epidemiol Rev. 2001;23(2):288-301. doi: 10.1093/oxfordjournals.epirev.a000807. [PubMed] [Cross Ref]

[18] Overcrowding. Horld Health Organisation. Available at [http://cdrwww.who.int/ceh/indicators/overcrowding.pdf]. Accessed on 12 December 17, 2014 